\title{
Noise Induced Workplaces and Noise Related Occupational Risks
}

\author{
Dilşad Akal \\ Inspector of Ministry of Science, Industry and Technology, Ankara, Turkey
}

Copyright $\mathrm{C} 2019$ by authors, all rights reserved. Authors agree that this article remains permanently open access under the terms of the Creative Commons Attribution License 4.0 International License

\begin{abstract}
Noise is broadly defined as unwanted sound that generally prevents people from performing at maximum ability and efficiency. Following air and water pollution, noise pollution is the third most critical environmental subject. Noise can be industrial noise, military noise, traffic noise, other kinds of environmental sourced noises, etc. Exposing noise by such ways can result in increased nervous tension with associated psychological effects, some impairments to the audio-sensory mechanism, and lead to premature and/or permanent loss of hearing. Statistics show that among worldwide, exposing the high doses of noise, hearing loss and tinnitus are significant public health issues and the prevalence of these conditions among employees in industry is significantly greater than the general public. This study is a compilation of literature which presents noisy workplaces, negative effects of noise on workers' health and the prevention plan of negative effects. In this research, the current situation about noise exposure in workplaces and its negative effects on workers are presented according to the statics and literature in Turkey and around world. After drawing the present frame of the picture, some recommendations will be given in order to prevent noise exposure and its negative side effects in industry.
\end{abstract}

Keywords Noise, Exposure, Employees, Literature

\section{Introduction}

One of the most widespread workplace hazards is noise. Due to the exposure of this hazard, hearing loss is the main occupational disease. During the $18^{\text {th }}$ century, the occupational hygienist Ramazzini pointed out the ears of copper workers are suffered from noise dangerously. During the industrial revolution, the workers who work in the boiler production process, started to have hearing problems. Most of them have lost the hearing capacity, so the term of boiler disease appeared. Still today noise exposure both environmentally and occupational can affect public health significantly and has a remarkable influence on the human activities [1]. WHO (World Health Organization) demonstrated that noise exposure affects hypertension, cardiovascular risks and sleep disturbance [2]. Some employees in some special occupations expose to noise $24 \mathrm{~h}$ or even more. Examples can be counted as carrier crew, textile industry workers, oil-platform workers, over-the-road truck drivers, agricultural workers, call center operators, heavy-industry workers etc. Noise can be grouped into four types. These are: ambient, impulsive, non-steady and steady ones. Ambient type has measurable intensity. The impulsive one consists one or more bursts of sound energy. Non-steady noise has level shifts significantly during the period of observation. And steady type of noise has negligibly small fluctuations of level within the period of observation. Generally the industrial noise exposure can be counted as impulsive or non-steady types of noise especially in heavy industry. However, the employees who expose these types of noise generally do not aware of the risk. This situation makes the condition even more risky.

Today in Turkey, there exist 665.288 dangerous and very dangerous workplaces and nearly all of them are noisy places. Approximately 1.500 .000 employees suffer from noisy work-environments and more than 200.000 of them suffer from hearing loss via occupational noise [3]. Around world; in USA for example, nearly 30 million employees expose to dangerous levels of noise in working environments. $8.5 \%$ of employees in Japan and $10 \%$ of employees in Denmark are noticed in literature to have hearing loss due to high noise exposure at work [4].

The sources of noise in industry can be: machines, the whole production process, engines like power or heat, pumps, collectors, tubes or pipes, blowers, caterpillars and similar motor vehicles and also human. Except the machines including in the production process, there are some other sources that increase the risk of exposure such as air conditioners, cleaning machines etc.

The negative health effects of industrial noise can be physical, physicologic and physiologic. The noise 
exposure decreases the efficienciy of working capacity of an employee [5].

Physical effects: can be permanent or temporary hearing loss. For physiologic effects: blood pressure increases, circulation disorders can occur, heart rhythm disorders can be seen. In the physicologic effects: behavior disorders and sudden blazings can be seen. Performance effects: can be defined as, decreasing in work efficiency, having trouble on concentrating during working period. The general negative effects of noise on human health can be: hearing sense damage, sleep problems, nervosity, decrease of work efficiency, quick temper and speaking barrier.

Table 1 shows the dose-response effects of noise on human health [6].

Table 1. Dose-response effects of noise on human health

\begin{tabular}{|c|c|}
\hline Dose (dB) & Response \\
\hline $30-65$ & $\begin{array}{c}\frac{\mathbf{1}^{\text {st }} \text { degree: }}{\text { Discomfort }} \\
\text { Anger } \\
\text { Concentration and sleep disorders }\end{array}$ \\
\hline $65-90$ & $\begin{array}{c}\mathbf{2}^{\text {nd }} \text { degree: } \\
\text { Alteration of heart beat } \\
\text { Increasing of respiration } \\
\text { Decreasing of brain pressure }\end{array}$ \\
\hline $90-120$ & $\frac{\mathbf{3}^{\text {rd }} \text { degree: }}{\text { Head ache }}$ \\
\hline $120-140$ & $\begin{array}{l}4^{\text {th }} \text { degree: } \\
\text { Failure on inner ear }\end{array}$ \\
\hline $140>$ & $\begin{array}{c}\mathbf{5}^{\text {th }} \text { degree: } \\
\text { Eardrum rupture }\end{array}$ \\
\hline
\end{tabular}

According to Table 1, depending on the increasing of dose values, response becomes more serious. In terms of work performance, noise can cause work accidents in terms of distributing attention and negatively affects memory.

Age, gender, previous traumas on ear, previous exposure to high intensity of noise and working with chemicals such as $\mathrm{CO}, \mathrm{CS}_{2}$, mercury vapor and the physical factors like vibration and heat all affect sensibility of noise [7].

Intensity of noise is the most important factor has the role on occupational deafness. A worker can work for 8 $\mathrm{h} /$ day at a noise level of $80-85 \mathrm{~dB}$ with having no hearing problems. Negative effects of noise can accumulate with time and irreversible results can be obtained. The damage process is irreversible. Once an employee had the hearing problem, it is impossible to be healthy again. The occupational deafness can be classified into two groups such as temporary and permanent. The temporary deafness can be defined as tiredness of the ear. However once permanent deafness is occurred, even if the noise is eliminated, it will stay [8].

Noise exposure has the economic disadvantages for companies also. For example, if a work accident or occupational disease has occurred once due to noise, employer will lose money in because of treatment and gain the loss time due to absenteeism. Absenteeism is another problem for employers. Due to work accidents or occupational diseases, employees can keep away from work. This situation can cause work loss. This is a negative condition for economy and lessens work yield.

The characteristics of hear loss due to noise can be bilateral: the first loss occurs at $4000 \mathrm{~Hz}$ frequency, later affects conversation frequencies. However hear loss does not have any treatment, if exposure is eliminated, it will not improve anymore [8].

\section{Purpose}

This is a brief study of occupational noise exposure and negative health effects on workers. With the help of this study, the frame of condition will be drawn and some recommendations will be given in order to prevention. Occupational diseases are $100 \%$ preventable. If the agent is eliminated from the working environment, the disease will not appear any more. However, once hear loss is occurred, the process is irreversible, but if factors are eliminated, will not improve any more.

\section{Materials and Methods}

According to SGK-TURKEY (Social Security Association-Turkey) 2016 data, 510 employees were diagnosed from occupational diseases. And nearly $60 \%$ of these have hearing problems [3]. In Turkey, approximately 2.500 workplaces exist. Half of them are heavy industry. In heavy industrial zones, noise exposure is the main risk factor. So, $60 \%$ of the result is inevitable. In industrial cities like Istanbul, Bursa, Izmir and Adana, occupational noise exposure is major problem around employees. Around these cities where textile industry is well-developed, $75-80 \%$ of employees occupied in this sector suffer from hearing disorders. The machines which make continuous vibration make also high intensity of noise.

As mentioned before call centers are another risky sector in terms of noise. The workers work in open office environment. Usually 200-1000 employees work in the same area, when they talk to each other and answer calls, because of this a continuous noise can occur during the working time. This continuous noise annoys employees. This exposure also causes nervosa around employees and this causes some other complaints. According to a research study carried through call centers in Turkey, lots of health and safety risks are investigated including noise. The result is the more the employee expose to the noise, the more complaints increase and he gets nervous. Nervosity entails the other gripes such as musculoskeletal complaints. Also workers generally suffer from head ache in noisy work environments [9]. The main handicap is both the employers and employees do not aware of the risk. Usually employees get used to work in noisy environments because of decreasing the hearing capacity. When an employee get 
used to noise, this means he will lose hearing ability or even become deaf. Minimum 2 years working at noisy workplaces can cause an occupational disease which sources from noise. Exposure to $4000-6000 \mathrm{~Hz}$ frequency at workplaces at least 30 days may cause permanent deafness [2]. At this situation, employee can hear 500-2000 $\mathrm{Hz}$ frequency levels, so he/she does not aware of being deaf. This will cultivate the situation. For occupational deafness, when aspect is run away, the disease will not improve any more.

Unfortunately in developing countries, the health and safety precautions and education about that topic is ignored by employers, employees and the specialists who deal with this topic. Because of this, prevalence of the occupational diseases and the work accidents are higher. As a result lots of workers die, become disabled or become ill every year according to the statics.

\section{Discussion}

Hear loss does not have a specific treatment, however it is a preventable pathology, so the prevention of noise is so important.

Prevention of noise can be taken three steps as;

1. Prevention at source

2. Prevention at ambient

3. Prevention on worker

Prevention at source is the most important step for preventing noise exposure. Because preventing at source may ensure in a broad sense of prevention. This may avoid expanding noise to the ambient. Prevention at source includes some technical recruitments. These can be choosing machines that make less noise or using sound proof equipment or placing the noisiest machines as far as from the worker. Vibration prevention is a good alternative in order to lessen the noise exposure. Periodical maintenance of the machines play important role in the perspective of decreasing the noise level exposure.

Prevention at ambient means to lessen the ambient noise level. This can be done by noise mapping. First, ambient noise should be measured according to the standards and by professionals. The measured values should be compared with the permissible limit values. The values above the limit values should be marked as risky zones. And while working around these zones the prevention methods should be applied.

Prevention on worker means that preventing the worker who expose to the noise. Using personal protective equipment (PPE) is the main factor at this step. But this should be the last step of prevention. After all the prevention methods have been used, such as prevention at source and prevention at ambient, the last choice should be used prevention on worker. This means personal protection and only supplies self protection. However the other methods are suitable for mass protection. While considering the limit values and using PPE, warning and danger limit values should be taken into account. Using PPE needs special attention. The PPE should be suitable for the person who uses it. And the periodical maintenance should be done properly.

$A$ warning limit value ( $85 \mathrm{~dB}$ ) that sets the noise level under which there is very little risk of hearing impairment to an unprotected ear for eight-hour exposure.

A danger limit value $(90 \mathrm{~dB})$ that sets the noise level above which hearing impairment and deafness may result from an eight-hour daily exposure of unprotected ear.

The equipment should be adaptable with the employee. And the employee must know how to use it and the periodical change or cleaning are important factors, too. The periodical maintenance of the equipment should also be done.

Also periodical physical examinations are very important if there exists noise in the working environment. Figure 1 is an example of audiometric screening examination. This figure shows the response to the frequency of noise in $\mathrm{kHz}$ of both left and right ears. In this figure, the right ear seems in trouble because of exceeding referred values. At $8 \mathrm{kHz}$, the hearing level exceeds the warning values. For the left ear, the situation is reverse because the hearing frequencies are below the warning values. 


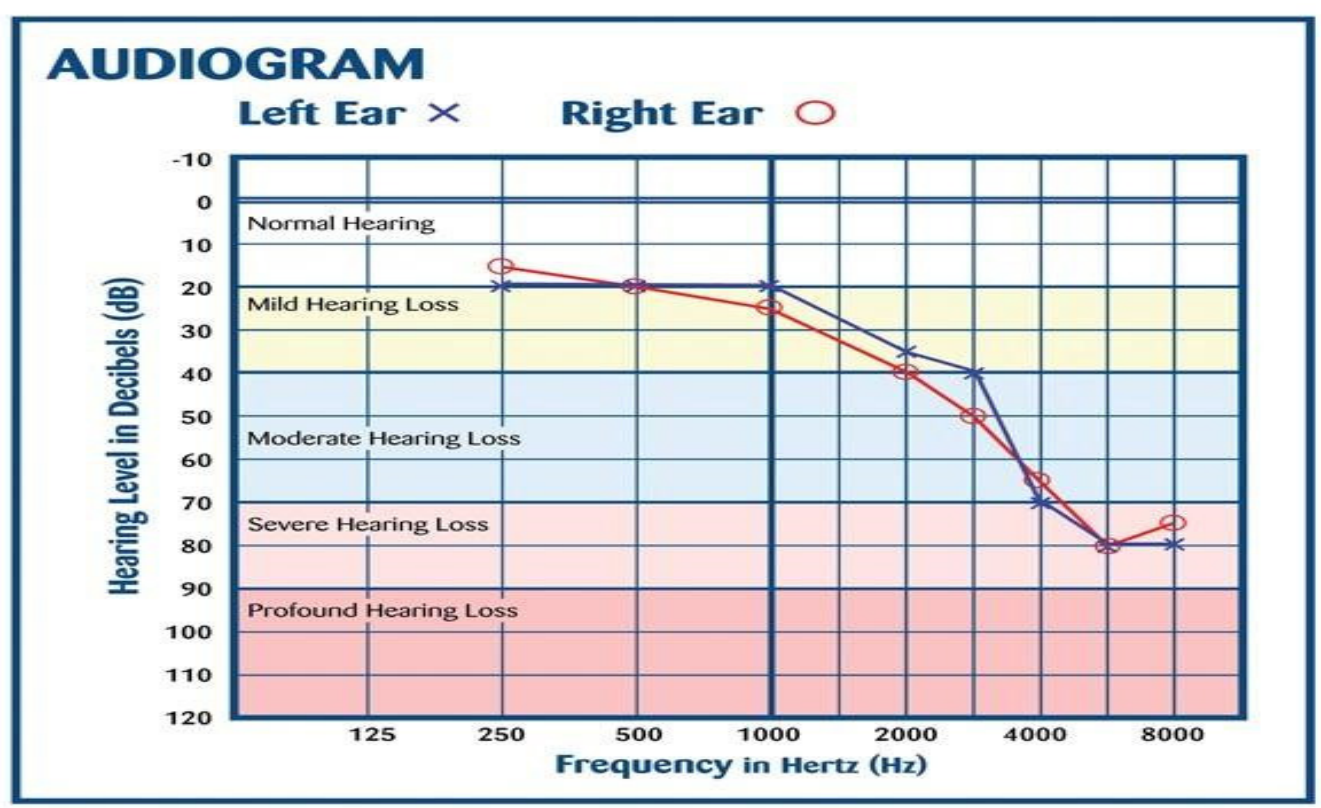

Figure 1. Audiometric screening

If anything wrong is detected through the examination, the treatment should be started. Also, the exposure time should be lessened of the workers who expose the noise in the working environment. Like these situations, rotation between employees can be an alternative. Other workers should be protected who work in the same environment and expose to the same level of noise even if he does not have anything wrong with his hearing capability.

\section{Conclusions}

In Turkey, 6331 numbered Law and related legislations organize existing health and safety conditions of workers. However there are still many workplaces that do not coherent with these regulations and there are so many workers and employers who do not aware of them. In order to get over this negativity, education plays an important role. Both employers and employees should be educated. Including negative effects of noise, prevents employees from negative health and safety conditions. There are some duties both for employers and employees. The duties of employers are:

- He must be responsible for reducing of all appropriate means exposure of noise.

- He should make the organizational planning required to prevent the risks due to noise.

- He should educate the employees in order to prevent themselves from the negative health effects of exposure.

The duties of employees are:

- Employees should abide by instructions given by professionals or employers in order to prevent noise.
- $\quad$ They should make use of noise control devices and techniques.

- $\quad$ They should be willing to undergo the prescribed medical examination periodically.

- $\quad$ They should use Personnel Protective Equipment (PPE) truly.

For noise exposure, in the workplaces the alarming situation is getting used to noise. Because if the employee says that 'I am getting used to noise'; unfortunately this means 'I am becoming deaf'.

In the perspective of health and safety to achieve zero risk at workplaces usually seems impossible, but it is possible to approach it, so the specialists who deal with this subject should target zero risk.

\section{REFERENCES}

[1] Job, R.F.S 1996, The influence of subjective reactions to noise on health effects of the noise, Environ. Int. 22:93-104.

[2] WHO (World Health Organization), Night noise guidelines for Europe, WHO Regional Office for Europe, URL http://www.euro.who.int/data/assets/pdf file/0017/43316/E92845.pdf, 2009.

[3] SGK, 2016: http://www.sgk.gov.tr/wps/portal/sgk/tr/kurum sal/istatistik/sgk_istatistik_yilliklari

[4] Oppong ,S 2015, Risk chain process model: Linking risk perception to occupational health, Siggurnust, 57:25-34

[5] Kujawa SG, Liberman MC 1996, Adding insult the injury: Cochlear nerve degeneration after "temporary" noise-induced hearing loss. Neurosci 29(45):14077-14085 
[6] Reeves AG, Swenson RS 2008, Disorders of the nervous system. /http://www.dartmouth.edu/ dons/part1/chapter6.; Accessed12.1.13.

[7] Public health and welfare criteria for noise July 1973. Environmental Protection Agency, Washington (DC)

[8] Burns W, Robinson D.1970 Hearing and noise in industry. London: Her Majesty's Stationery Office

[9] Occupational noise exposure, 1996. 29 CFR 1910.95, US Department of Labor

[10] Akal D., 2016, Evaluation Of Call Centers By Using Electromagnetic Area Measurement In Terms Of Safety And Health At Work, Gazi University Graduate School Of Natural And Applied Sciences, PhD Thesis 